\title{
Statistical analysis of wave parameters in the north coast of the Persian Gulf
}

\author{
A. Parvaresh, S. Hassanzadeh, and M. H. Bordbar \\ Department of Physics-Faculty of Sciences-University of Isfahan, Isfahan 81744, Iran
}

Received: 11 November 2004 - Revised: 3 May 2005 - Accepted: 8 June 2005 - Published: 15 September 2005

\begin{abstract}
In this study we have analysed wind and wave time series data resulting from hourly measurements on the sea surface in Bushehr, the northern part of the Persian Gulf, from 15 July to 4 August 2000. Wind speed $\left(U_{10}\right)$ ranged from 0.34 to $10.38 \mathrm{~m} / \mathrm{s}$ as alternating sea and land breezes. The lowest wind speed occurs at about midnight and the highest at around noon. The calculated autocorrelation of wind speed data shows that when the sea-land breeze is strong, the land-sea breeze is weak and vice versa. The significant wave height $\left(H_{s}\right)$ varies between 0.10 to $1.02 \mathrm{~m}$. The data of the present study reflects mostly the local waves or the sea waves. The calculated correlation between wind and wave parameters is rather weak, due to the continuous change in the wind direction. Wave height distribution follows the well-known Rayleigh distribution law. The cross correlation analyses between $U_{10}$ and $H_{s}$ reveal a time lag of $4 \mathrm{~h}$. Finally, we have shown that the time series of $U_{10}, H_{s}$, and wave period are stationary. We have modeled these parameters by an auto regressive moving average (ARMA) and auto regressive integrated moving average (ARIMA) models.
\end{abstract}

Keywords. Oceanography: physical (Air-sea interactions; Surface waves and tides; Upper ocean processes)

\section{Introduction}

During the daytime, in a calm atmosphere (absent of gradient wind), solar radiation heats up the land surface more rapidly than the water surface, causing a horizontal temperature gradient between the land and sea surface air. The air over the land heats up and hence expands more rapidly than the air over the sea. Due to the hydrostatic conditions, the vertical pressure gradient is greater in the cooler air over the water than in the warmer air over the land. This means that, at a given height, the pressure is higher over the land than over the water. This pressure gradient produces a slight flow of

Correspondence to: S. Hassanzadeh

(shz@sci.ui.ac.ir) air from the upper levels above the land to the upper levels above the sea. This leads to an increase in the pressure over the sea, so that air subsidence occurs. Departure from hydrostatic equilibrium leads to the flow from the sea to the land, in the lower level. This is called the sea breeze. At night time the reverse process occurs and a land breeze takes place. The onset of the sea breeze is usually marked by an increase in wind speed, a decrease in temperature and an increase in humidity. If a gradient wind exists, the effects of the sea breeze may be more difficult to detect. Sea and land breezes occur more frequently and with greater regularity in the tropics than in the middle and high latitudes (Atkinson, 1981). Sea breeze speed usually ranges between 6 and $10 \mathrm{~m} / \mathrm{s}$ and from 3 to $5 \mathrm{~m} / \mathrm{s}$ for a land breeze. The land breeze is always weaker than the sea breeze. The on/off shore extent of the sea breeze is about $10-20 \mathrm{~km}$ (Hsu, 1988).

Sea surface waves are caused by momentum exchange at the air-sea interface and enhanced energy and momentum flow between the atmosphere and the ocean. Winds moving across open waters create pressure differentials on the water surface and wave development depends on wind speed, fetch, and duration. The wave generation mechanisms are highly complex, involving nonlinear processes, where the physics of the process is not fully understood. According to the Philips theory (Inoue, 1967) wave energy increases linearly with time, in the early stage of wave growth. After this stage, according to Mile's theory (Inoue, 1967), shear flow instability in the coupled air-water system results in an exponential growth rate of wave energy.

Ocean waves are often irregular and multi-directional. They are usually described by a superposition of many monochromatic wave components of different frequencies, amplitudes and directions.

Investigation of the wave components could provide valuable information for several practical applications, such as wave forces on offshore structures and other coastal works, shore protection measures, irregular wave run-ups, etc.

As the distance away from the immediate region of wave generation increases, or as the wind speed reduces, waves become "swell". Since longer waves travel faster than shorter 


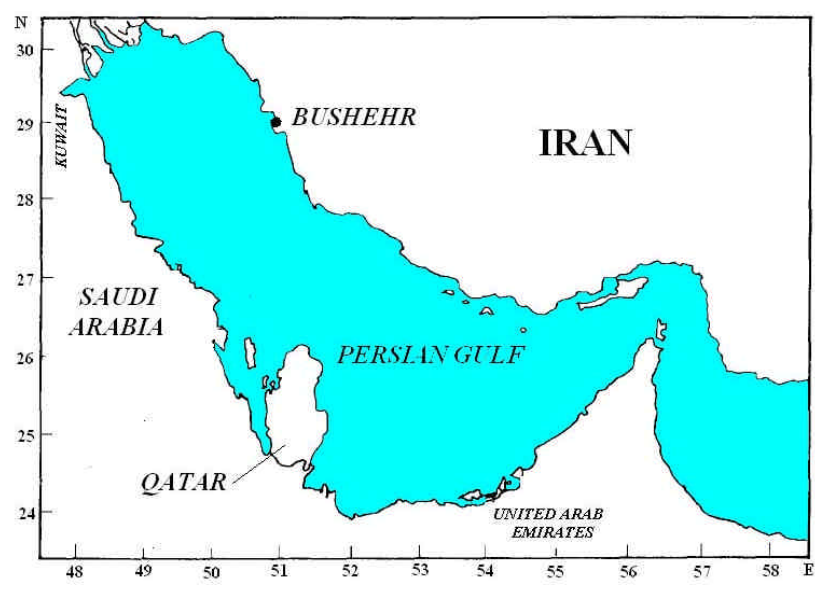

Fig. 1. Persian Gulf map (Ramesht, 1988).

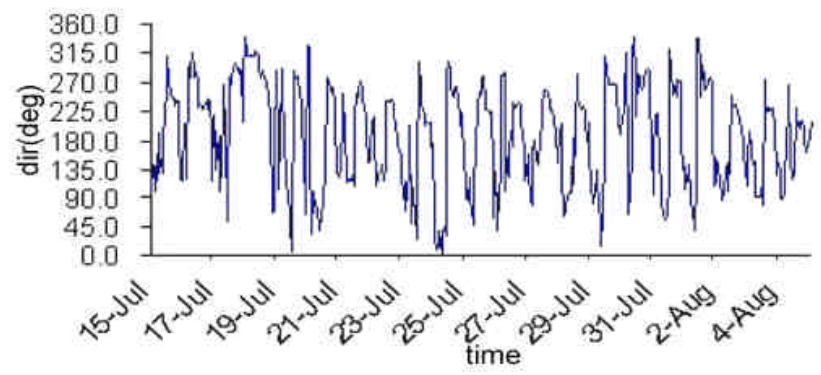

Fig. 2. Hourly time series of wind direction $(U D)$ against time (24$\mathrm{h}$ interval).

ones, the wavelength and period of the swells gradually increase with time and distance from the source. Swells decrease in amplitude, due to spreading and friction, so they are usually linear, coherent and have small-amplitude. Variation of swell periods is between $8-12 \mathrm{~s}$, but that of sea waves is between 1.5-5 s (Brockwell and Davis, 1996).

\section{Study area and data sources}

The Persian Gulf is a shallow, semi-enclosed sea and its climate is arid, due to the excess of evaporation over precipitation and river run-off. The high evaporation and saline water lead to anti-estuary circulation through the Hormuz Strait. The area of Persian Gulf is about $2.26 \times 10^{5} \mathrm{~km}^{2}$, with an average depth of $35 \mathrm{~m}$.

All measurements were made at Bushehr $\left(28^{\circ} 59^{\prime} \mathrm{N}\right.$ $50^{\circ} 50^{\prime} \mathrm{E}$ ). Figure 1 shows the map of the study area. We have used the hourly time series wave and wind data measured by the Ports and Shipping Organization of Iran.

Wind parameters were measured at the coastal station in Bushehr and wave parameters were measured by a buoy (S4 model) at $29^{\circ} 2^{\prime} 12^{\prime \prime} \mathrm{N}, 50^{\circ} 39^{\prime} 10^{\prime \prime} \mathrm{E}, 12 \mathrm{~km}$ from the Bushehr coast, where the water depth is $15 \mathrm{~m}$, and the coastal line direction is NW-SE.

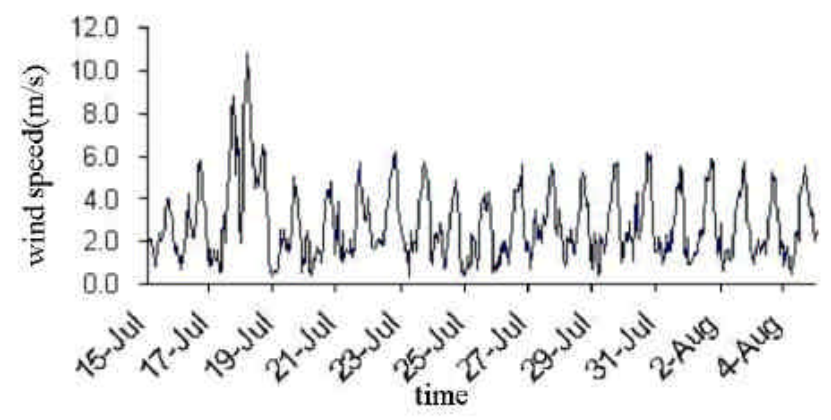

Fig. 3. Hourly time series of wind speed $\left(U_{10}\right)$ against time (24-h interval).

Wave characteristics are often measured by means of submerged pressure transducers. The use of this instrument imposes some problems, the most important being the bias of its output due to the dynamical effect of the relative motion of water particles.

The usual analysis of zero-up crossing properties in a wave record requires digitization of the record at a finite sampling rate. Always in this buoy, large wave heights could be determined with relative errors of $0.5 \%$ for $\Delta / T_{\text {avg }}<1 / 20$, where $\Delta$ represents the sampling time interval and $T_{\text {avg }}$ is the spectral mean period. Other errors include statistical, numerical, sea state bias and the assumption of linear wave theory. Usually the errors do not depend on the depth of the sea, and are greater for higher wave numbers. The errors are greater for a high sea state.

\section{Wind characteristics in the area}

One-hourly time series of wind direction and wind speed observed during the 21-day period (15 July-4 August 2000) are shown in Figs. 2 and 3. Wind data were recorded by the standard buoy, whereas wave parameters were obtained from the raw data with hourly intervals. Data were recorded continuously. It should be mentioned that, although the predominant wind is NW-SE wind (shamal), the data we used are due to temporal (summer) wind (Ramesht (1988)).

In Fig. 2 the direction of wind $(U D)$ shows variations between $0^{\circ}$ and $330^{\circ}$. This is in agreement with the climatological data available from the meteorological stations for the northern coast of the Persian Gulf. Figure 3 shows that the wind speed at $10 \mathrm{~m}$ above sea level $\left(\mathrm{U}_{10}\right)$ varies between 0.34 and $10.83 \mathrm{~ms}^{-1}$ with a characteristic diurnal oscillation. The lowest wind speed occurred about midnight and the highest speed around noon. The markings on the time-axis are made at 24-h intervals (starting on 15 July), in order that the diurnal pattern can be easily discernible.

In Figs. 4 and 5 wind speed is resolved into two components, along and across the shore. In Fig. 4 positive (negative) values indicates a sea (land) breeze. These figures show that the sea breeze occurs during the day and the land breeze occurs at nighttime. 


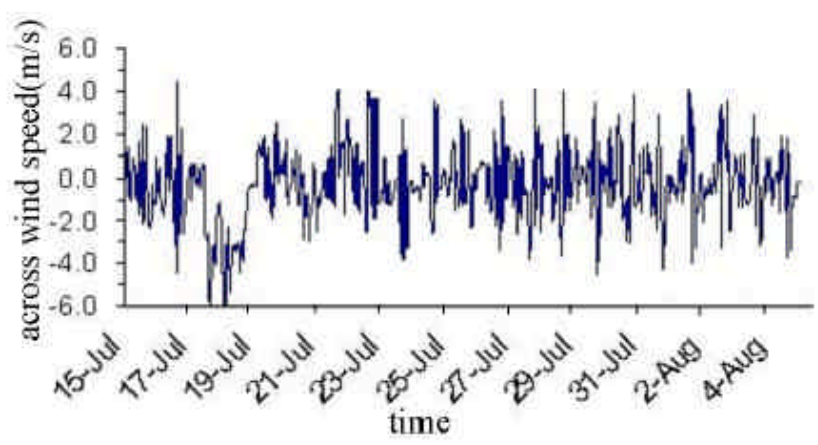

Fig. 4. Hourly time series of onshore wind against time (24-h interval).

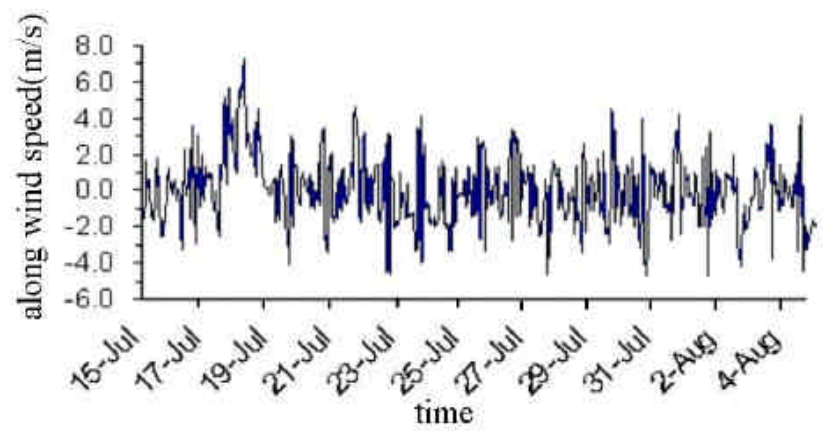

Fig. 5. Hourly time series of along shore wind against time (24-h interval).

The diurnal variations of wind characteristics in this area, especially near the coastal zone, are normally attributed to land and sea breeze effects. Wind speed associated with the land-sea breeze is less than $6 \mathrm{~m} / \mathrm{s}$, but that of the sea-land breeze is greater. The change in wind speed and direction is almost simultaneous.

In this study, autocorrelation coefficients of wind speed data are calculated. These coefficients, with hourly intervals, are plotted versus time, in Fig. 6. Autocorrelation coefficients for a lag of 1 to $5 \mathrm{~h}$ are greater than 0.5 . Between lag 8 to $19 \mathrm{~h}$ the autocorrelation function is negative. The physical reason for this phenomenon is the air-sea temperature difference. During the day the land temperature is greater than the water temperature, so the local wind is directed onshore in the direction of lower surface pressure. At night, the water temperature is less than the land temperature, but the magnitude of the difference is less and the land-sea breeze is weak. Figure 6 shows that the autocorrelation function has a minimum and a maximum at lag 15 and a maximum at lag 24 . The minimum occurs when the maximum inverse correlation between the sea-land and the land-sea breeze happens. The maximum on lag 24 shows a diurnal cycle in the wind speed.

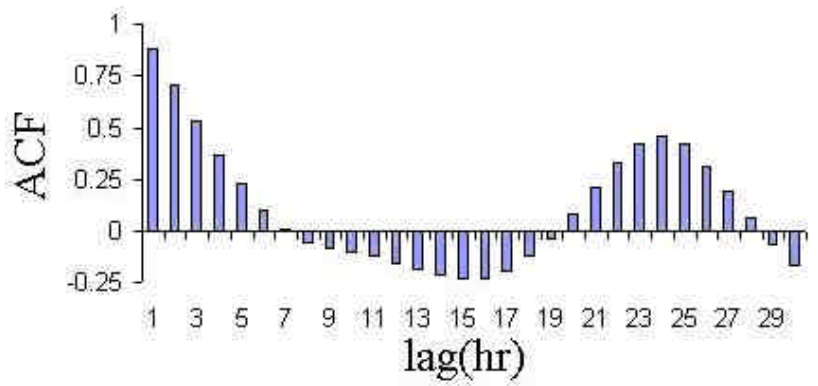

Fig. 6. Wind speed autocorrelation function against time.
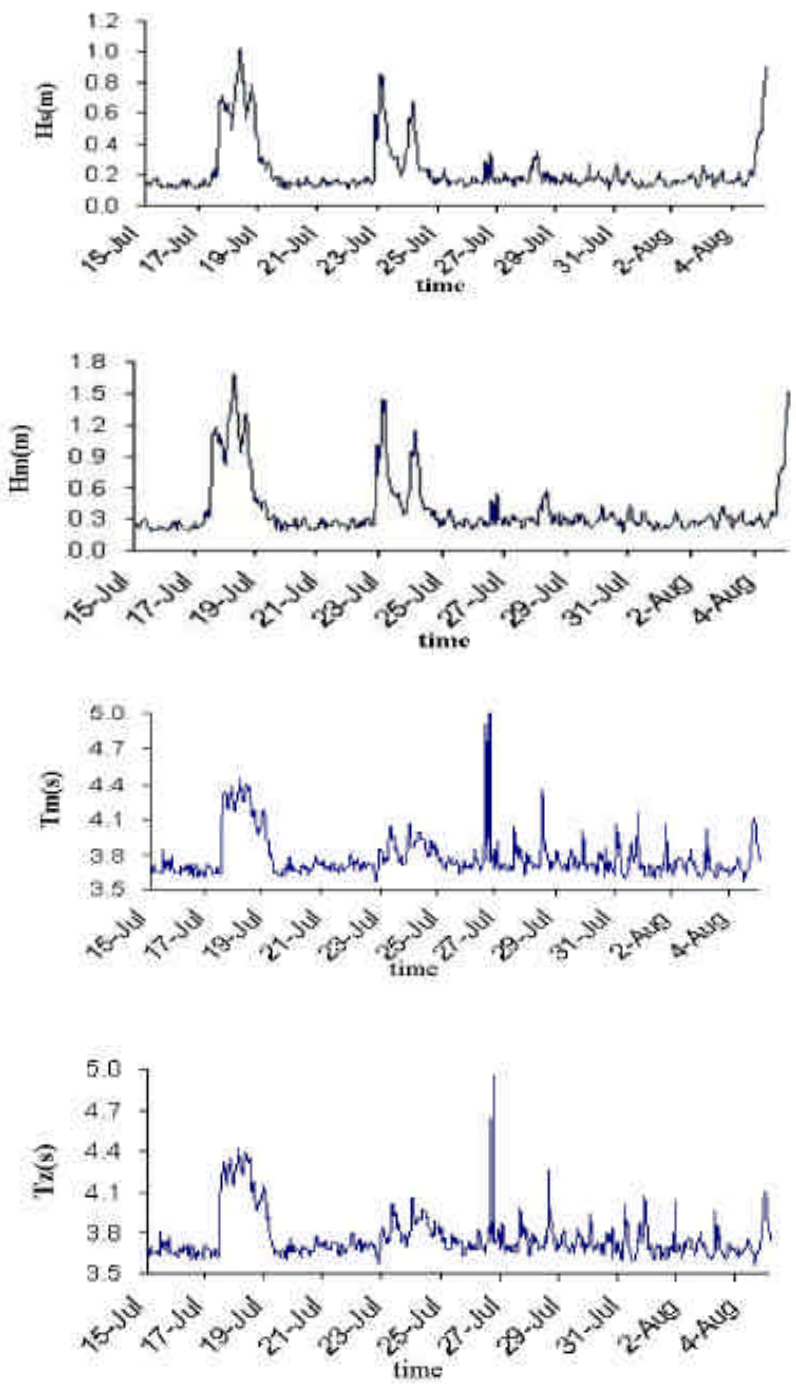

Fig. 7. Hourly time series significant wave height $\left(H_{S}\right)$, maximum wave height $\left(H_{m}\right)$, wave period corresponding to $H_{m}\left(T_{m}\right)$ and zero crossing period $\left(T_{z}\right)$.

\section{Wave characteristics}

The time series of wave parameters are shown in Fig. 7. In this figure the significant wave height, $H_{s}$, is defined as the 


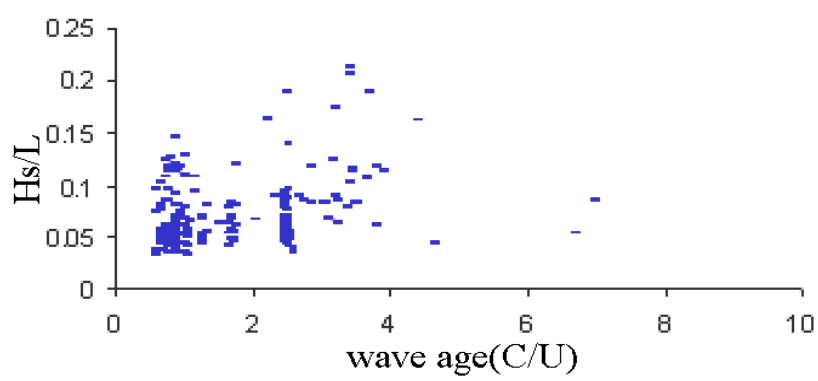

Fig. 8. Wave age $\left(C / U_{10}\right)$ vs. wave steepness $\left(H_{S} / L\right)$.

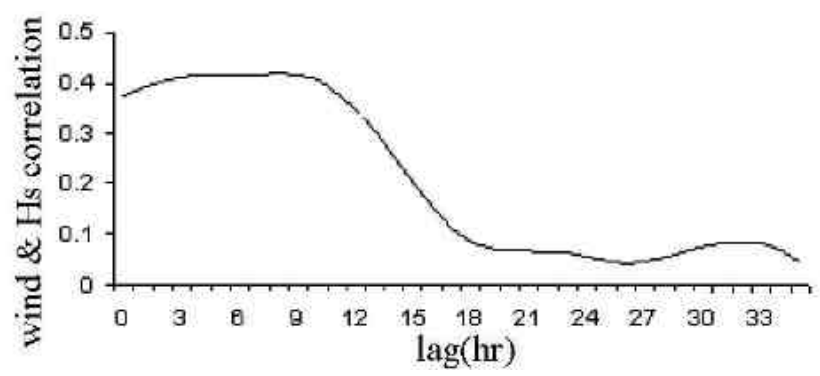

Fig. 9. Variation of cross-correlation for wind speed $\left(U_{10}\right)$ and significant wave height $\left(H_{S}\right)$ with time-lag.

mean of the highest one-third of the waves present in the sea and the maximum wave height, $H_{m}$, is the maximum vertical distance between the highest crest to the lowest trough; $T_{m}$ is the wave period corresponding to $H_{m}$, and $T_{z}$ is the mean zero-up crossing period of the wave field. As is seen, each of these parameters varies between 0.10 to $1.02 \mathrm{~m} ; 0.15$ to $1.70 \mathrm{~m} ; 3.56$ to $4.59 \mathrm{~s}$ and 3.57 to $5.255 \mathrm{~s}$, respectively. Thus, the prevailing wave conditions mostly reflect the sea state 2 and 3 codes (WMO 1988) during the observation period.

The dimensionless wave parameters, namely, the wave steepness $\left(H_{S} / L\right)$ and the wave age $\left(C / U_{10}\right)$, where $C$ is the phase speed, are often used to determine the nature of the sea state. Wave steepness is usually expressed as the ratio between the significant wave height and the wave length, of the peak period. Thompson et al. (1984) gave a classification scheme for ocean waves based on $\left(H_{S} / L\right)$ criterion namely, sea young swell, mature swell and old swell. According to their classification, locally generated waves or sea waves have steepness values greater than 0.025 . Figure 8 does not show any correlation between wave age and wave steepness. This figure mainly reflects local waves or sea waves as $\left(H_{S} / L\right)$ is greater than 0.025 . Younger waves are steeper than the older ones (Thompson et al., 1984).

\section{Statistical correlation between wave and wind param- eters}

Statistical correlations obtained among various analysed wave parameters and wind speed are given in Table 1. Wave
Table 1. Correlation coefficients of the analysed wave parameters and wind speed.

\begin{tabular}{|c|c|c|c|c|c|c|}
\hline & $U_{10}$ & $H_{S}$ & $H_{m}$ & $H_{\text {avg }}$ & $T_{z}$ & $T_{m}$ \\
\hline$U_{10}$ & & 0.376 & 0.373 & 0.375 & 0.297 & 0.295 \\
\hline$H_{S}$ & & & 0.999 & 0.998 & 0.675 & $*$ \\
\hline$H_{m}$ & & & & 0.998 & 0.671 & $*$ \\
\hline$H_{\text {avg }}$ & & & & & 0.670 & $*$ \\
\hline$T_{z}$ & & & & & & 0.996 \\
\hline
\end{tabular}

* Indicates that the correlation coefficient values are not statistically significant.

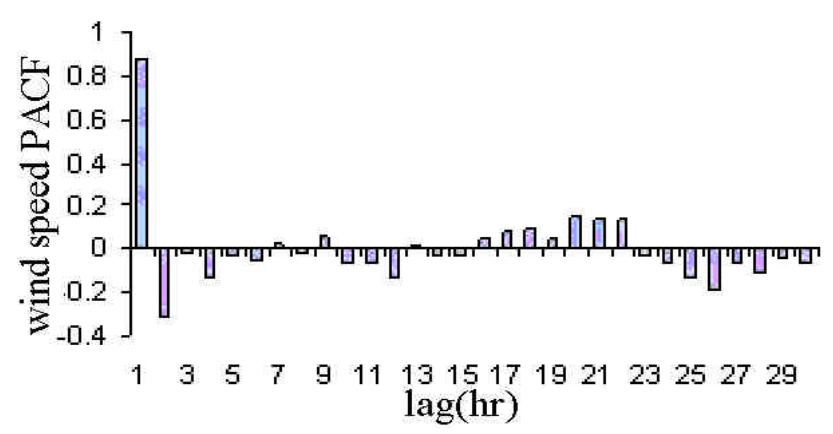

Fig. 10. Wind speed partial autocorrelation with 1-h time lag.

heights $\left(H_{s}\right.$ and $\left.H_{m}\right)$ and wave periods $\left(T_{z}\right.$ and $\left.T_{m}\right)$ show positive and low correlation against wind speed $\left(U_{10}\right)$.

Positive correlation in wind speed $\left(U_{10}\right)$ against $H_{s}$ and $H_{m}$ is due to the increase of wind energy. Low correlation coefficients are perhaps due to the diurnal change in wind direction. When the wind direction varies with time, the role of wind speed on the wave height growth decreases. When the wind and wave directions are opposite from each other, the wind speed applies an opposing stress against the waves and therefore the wave height growth is negative. So in this area the correlation between wind speed and wave height is weak. The correlation between onshore and along-shore wind speed and wave parameters is weak as well.

The positive correlation of wave periods with wind speed, which is observed in this case, reveals the complex nature of the wave period evolution during the active wave growth conditions. $H_{m}$ shows a better correlation with $U_{10}$ than $T_{m}$. The correlation coefficient values obtained for $T_{m}$ against $H_{s}$ and $H_{m}$ are not shown in Table 1 , since they are not statistically significant.

A strong positive correlation (corr. coeff. $=0.999$ ) exists between $H_{s}$ and $H_{m}$. The concept of statistically stationary wave heights was originally proposed by LonguetHiggins (1952). According to this concept, the ratios of significant wave parameters (statistical averages) are expected to be constant. The theoretical value proposed for $H_{m} / H_{s}$ is 1.53 (Longuet-Higgins, 1952). Our analyses show that this ratio is 1.66. John (1985) suggested that $H_{m} / H_{s}$ obtained with different data sets varies between 1.29 and 1.91. It is 
Table 2. Statistical coefficient of wind speed time series model.

\begin{tabular}{ccccc}
\hline Variable & Coeff. & Std. Error & t-Statistic & Prob. \\
\hline$C$ & 0.3584 & 0.0553 & 6.4725 & 0 \\
SPEED $(-1)$ & 1.1495 & 0.0426 & 26.9650 & 0 \\
SPEED $(-2)$ & -0.3059 & 0.0426 & -7.1760 & 0 \\
R-squared & 0.7960 & Mean dependent var & 2.2870 \\
Adjusted R-squared & 0.7952 & F-statistic & 973.6508 \\
Durbin-Watson & 2.0138 & Prob(F-statistic) & 0 \\
\hline
\end{tabular}

Table 3. Statistical coefficient of significant wave height time series model.

\begin{tabular}{ccccc}
\hline Variable & Coeff. & Std. Error & t-Statistic & Prob. \\
\hline$C$ & 0.0089 & 0.0039 & 2.2774 & 0 \\
$H_{S}(-1)$ & 0.9676 & 0.0140 & 68.8966 & 0 \\
R-squared & 0.9045 & Mean dependent var & 0.2300 \\
Adjusted R-squared & 0.9043 & F-statistic & 4746.745 \\
Durbin-Watson stat & 1.9538 & Prob(F-statistic) & 0 \\
\hline
\end{tabular}

important to note that the length of the time series used for the wave analysis, as well as the differences in the wave measuring devices employed, may lead to the differences in the wave statistics derived from a given wave record. Our results generally agree with the Rayleigh distribution law. We have found $H_{1 / 10} / H_{s}$ to be 1.271 comparable to the Rayleigh value of 1.275 .

An important question is whether the waves begin growing when the sea-land breeze begins or whether a lag time $(\tau)$ exists between these two. From simple physical considerations one can safely assume a certain lag time for waves to grow as wind starts blowing over the sea surface. Therefore, we computed the cross-correlation between $U_{10}$ and $H_{s}$. The time history of any two sets of the time series records can be tested to know the general dependence of one set of data on the other (Bendat and Piersol, 1986).

Cross-correlation function $R_{u h}$, between $U_{10}$ and $H_{s}$, is defined as:

$R_{u h}=\lim (1 / T) \int U_{10} \times H_{s}(\tau+t) d t$,

where $T$ is the total duration of the time series record and $\tau$ is the time lag (Box and Jenkins, 1976). This function is plotted in Fig. 9 and reveals two peaks. The primary peak is between the lag of 3 to $11 \mathrm{~h}$ and the second one at $32 \mathrm{~h}$. The $R_{u h}$ values for these peaks are 0.41 and 0.12 , respectively. The second peak could be due to the presence of diurnal variability in the data $(24+(4+11) / 2 \sim 32)$. The first peak suggests that the wave field lags behind the wind by at least about $3 \mathrm{~h}$. The constant value of $R_{u h}$ between lag 4 to lag 11 is the result of the variation of the wind direction in this area.

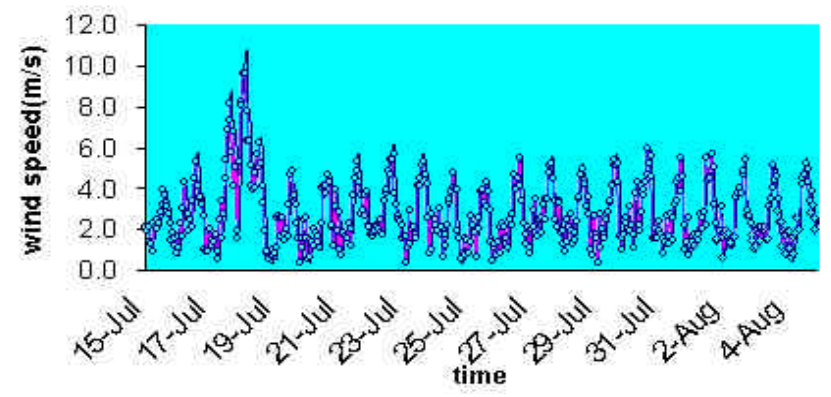

Fig. 11. Predicted (solid line) and measured (dotted line) wind speed $\left(U_{4.5}\right)$.

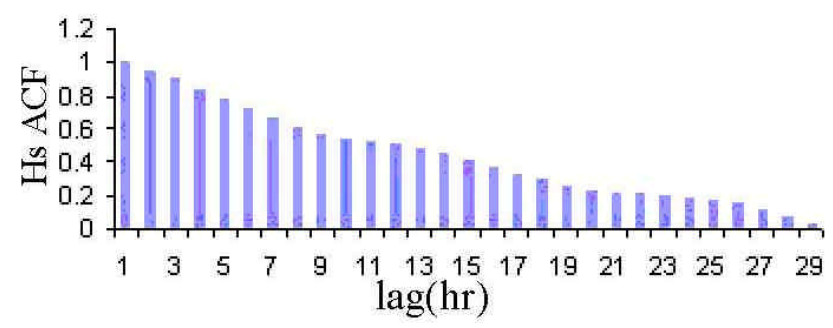

Fig. 12. Significant wave height autocorrelation with 1-h time lag.

\section{Prediction of wind and wave parameters by time se- ries modeling}

In this section the statistical models used will be described. The theoretical background described and the techniques used are presented. Consider the time series $\left\{X_{t}\right.$, : $t=0, \pm 1, \pm 2, \ldots\}$, i.e. a sequence of dependent random variables in time. The time series is stationary if

$F\left(X_{t_{1}}, X_{t_{2}}, \ldots X_{t_{n}}\right)=F\left(X_{t_{1+k}}, X_{t_{2+k}}, \ldots, X_{t_{n+k}}\right)$,

where $n, k, t_{1}, t_{2}, \ldots t_{n}$, are integer numbers and $F(\cdot)$ represents the joint probability distribution function of any $n$ random variables of process $\left\{X_{t}\right\}$. The time series is said to be weakly or second-order stationary, if the mean function is constant and the covariance between any two of them just depends on the time difference between them but not on time itself $\left(\gamma_{t, t-k}=\gamma_{0, k}\right)$. An important example of a weakly stationary process is the white noise $\left(a_{t}\right)$ process, which is defined as a sequence of independent, identical distribution of random variables. We shall usually assume that the white noise has a zero mean and denote its variance as $\left(\sigma_{a_{t}}^{2}\right)$ (Guedes Soares and Ferreira, 1996).

If the time series $X_{t}$ verifies a relation

$$
\begin{aligned}
X_{t}= & \varphi_{1} X_{t-1}+\varphi_{2} X_{t-2}+\cdots \varphi_{p} X_{t-p}+ \\
& a_{t}-\theta_{1} a_{t-1}-\theta_{2} a_{t-2}-\cdots \theta_{q} a_{t-q},
\end{aligned}
$$

where $\phi_{1}, \phi_{2}, \ldots, \phi_{p}, \theta_{1}, \theta_{2}, \ldots, \theta_{q}$ are unknown constants, it is said to be described by an ARMA model of order $p$ and $q$, respectively, where the time series should be stationary and $\left\{a_{t},: t=0, \pm 1, \pm 2, \ldots\right\}$ should be a white noise process. An ARMA $(p, q)$ model, in which the order $p$ is zero, is 


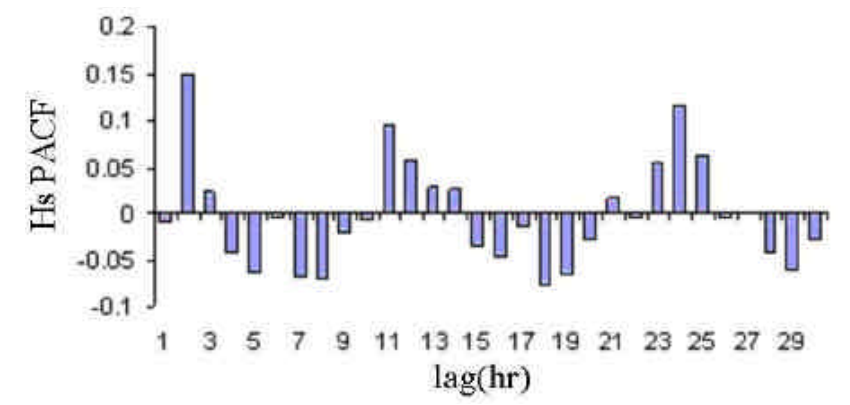

Fig. 13. Significant wave height partial autocorrelation with $1-\mathrm{h}$ time lag.

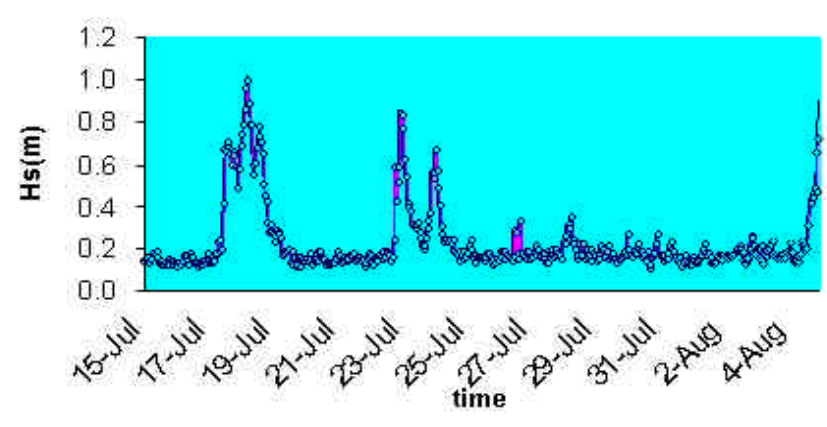

Fig. 14. Predicted (solid line) and measured (dotted line) significant wave height.

called the moving average of order $q-\mathrm{MA}(q)-$ and when the order $q$ is zero it becomes an autoregressive of order $p-\operatorname{AR}(p)$.

A time series $X_{t}$ is said to follow an ARIMA if the $d$ th difference $W_{t}=\Delta^{d} X t$ is a stationary ARMA process. If $W_{t}$ is $\operatorname{ARMA}(p, q)$, we say that $X_{t}$ is $\operatorname{ARIMA}(p, d, q)$. Differences can also be conveniently written in terms of $B$, as a backshift operator, i.e. $\Delta^{d}=(1-B)^{d}$. The ARIMA model is then expressed as

$\Phi(B)(1-B)^{d} X_{t}=\Theta(B) a_{t}$,

where $\Phi(B)$ and $\Theta(B)$ are:

$\Phi(B)=1-\varphi_{1} B-\varphi_{2} B^{2} \cdots \varphi_{p} B^{p}$
$\Theta(B)=1-\theta_{1} B-\theta_{2} B^{2} \cdots \theta_{p} B^{p}$.

Fundamental tools in time series analyses are the autocorrelation function $(\mathrm{ACF}), \rho_{k}$, and the partial autocorrelation function (PACF), $\phi_{k k}$, where $\rho_{k}$ and $\phi_{k k}$ are:

$\rho_{k}=\frac{\operatorname{cov}\left(X_{t}, X_{t+k}\right)}{\sqrt{\operatorname{var}\left(X_{t}\right)} \sqrt{\operatorname{var}\left(X_{t+k}\right)}}=\frac{\gamma_{k}}{\gamma_{0}}$

$\phi_{k k}=\frac{\operatorname{cov}\left(\left(X_{t}-\overline{X_{t}}\right),\left(X_{t+k}-\overline{X_{t+k}}\right)\right)}{\sqrt{\operatorname{var}\left(X_{t}-\overline{X_{t}}\right)} \sqrt{\operatorname{var}\left(X_{t+k}-\overline{X_{t+k}}\right)}}$,

respectively, and $\overline{X_{t}}$ stands for the best linear estimate of $X_{t}$ and subscript $t$ stands for $X$ value in time $t$. (Guedes Soares and Ferreira, 1996; Hidalgo et al., 1995).

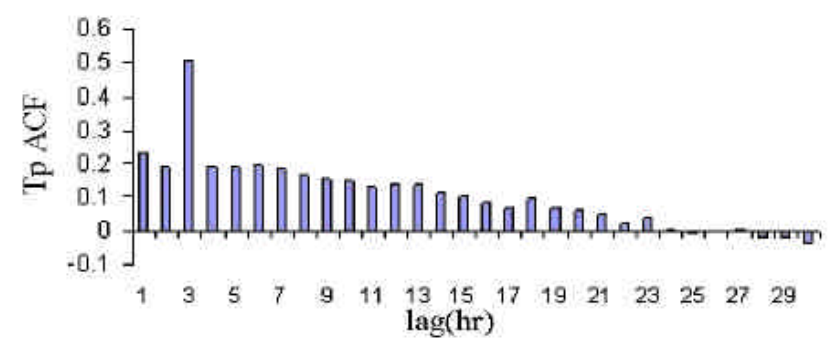

Fig. 15. Dominant wave period $T_{p}$ autocorrelation with 1-h time lag.

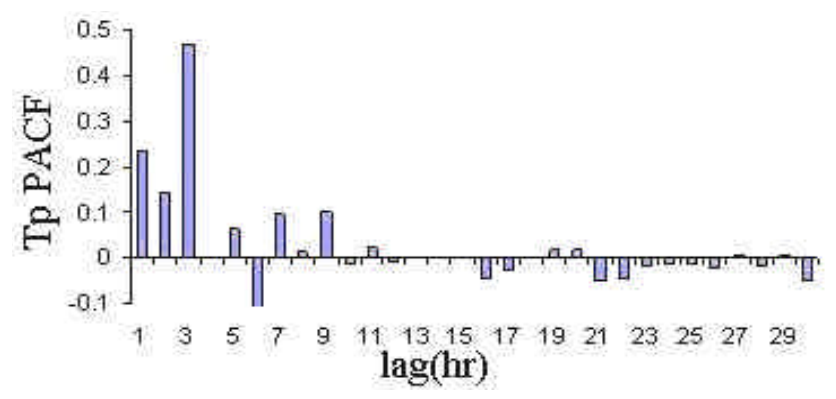

Fig. 16. Dominant wave period $T_{p}$ partial autocorrelation with 1-h time lag.

In this study we have examined whether the time series of wind speed, significant wave height, and wave period, are stationary. These parameters are modeled by ARMA and ARIMA models. We have used Eviews software and the time series have been evaluated by the Dickey-Fuller unit root test.

This test on wind speed data shows that this time series is stationary at $99 \%$ level. We have plotted ACF and PACF of wind speed data in Figs. 6 and 10. These figures show that the behavior of this time series is autoregressive, AR. By regression test on all lags, we found that the best predicted level relates to lags 1 and $2 \mathrm{~h}$. Adding other lags on regression has no effect on the prediction level. Adding moving average coefficients in this case is not efficient. Therefore, the best model in this case is autoregressive, AR. Coefficients of this model are given in Table 2. The table shows the following relation, with a prediction level of $79.6 \%$ :

$U_{t}=0.358+1.149 U_{t-1}-0.305 U_{t-2}$,

where $U_{t}$ stands for the wind speed at time $t(\mathrm{~h})$. The predicted and measured wind speeds are shown in Fig. 11.

The Dickey-Fuller unit root test on significant wave height $H_{s}$ shows that the significant wave height time series is stationary at the $95 \%$ level. ACF and PACF of this time series are plotted in Figs. 12 and 13, respectively. Regressions on all lags indicate that the best model for the $H_{s}$ time series is:

$H_{s, t}(m)=0.0089+0.976 H_{s, t-1}(m)$.

The predicted and measured significant wave heights are shown in Fig. 14. The statistical coefficients of this time series model are shown in Table 3. 
The Dickey-Fuller unit root test on dominant period $T_{p}$ shows that $T_{p}$ time series is stationary at $99 \%$ level. ACF and PACF of this time series are shown in Figs. 15 and 16. The best prediction level of the ARMA model for this time series is $20 \%$ level, and therefore the ARIMA model should be used for this time series. Using the ARIMA test for this time series, we found that the best model for this time series is:

$$
\begin{aligned}
& \left(1+1.761 B+1.325 B^{2}+0.5283 B^{3}\right)(1-B)^{2} T p_{t} \\
& \quad=-1.02 u_{t-2},
\end{aligned}
$$

where $u_{t-2}$ is the residual of two back lags, $u_{t}$ stands for $a_{t}$ and $T_{p}$ is the most probable period of the wave field. This model predicts $T_{p}$ at the $83.52 \%$ level. Statistical coefficients of this model are shown in Table 4 . The predicted and measured values of $(1-B)^{2} T_{p}$ are shown in Fig. 17 .

\section{Conclusions}

1. Observed winds $\left(U_{10}\right)$ behave as land and sea breezes, with the minimum speed occurring around midnight and the maximum around noon. The wind speed varied from 0.34 to $10.38 \mathrm{~m} / \mathrm{s}$.

2. Observed significant wave height $\left(H_{S}\right)$ and mean zeroup crossing period $\left(T_{z}\right)$ varied from 0.1 to $1.02 \mathrm{~m}$, and 3.56 to $4.95 \mathrm{~s}$ respectively. The wave conditions mostly reflect sea states 2 and 3 (WMO code).

3. Due to continuous variations of wind speed with time, correlations between wind speed and wave parameters show low values.

4. The wave height distribution follows the Rayleigh distribution law. The ratio of $H_{s} / H_{m}$ obtained with the present data is 1.75 .

5. Wave conditions mostly reflect local waves or sea waves.

6. There is no correlation between wave age and wave steepness. This is due to the fact that the wave never ages during the diurnal wind cycle. The waves are local waves.

7. Cross correlation of $U_{10}$ and $H_{S}$ reveals that waves lag behind wind by about $4 \mathrm{~h}$.

8. The time series of the wind speed $\left(U_{10}\right)$, significant wave height $\left(H_{s}\right)$ and dominant wave period $\left(T_{p}\right)$ are stationary at level 99\%, 95\% and 99\%, respectively. The best model and the prediction level of these parameters are:

$$
\begin{array}{cc}
U_{t}=0.358+1.149 U_{t-1}-0.305 U_{t-2} & R^{2}=79.6 \% \\
H_{s, t(m)}=0.0089+0.976 H_{s, t-1}(m) & R^{2}=90.4 \% \\
\left(1+1.761 B+1.325 B^{2}+0.5283 B^{3}\right)(1-B) & 2 T_{p, t} \\
=-1.02 U_{t-2} & R^{2}=83.5 \%
\end{array}
$$

Table 4. Statistical coefficient of dominant period Tp time series model.

\begin{tabular}{ccccc}
\hline Variable & Coeff. & Std. Error & t-Statistic & Prob. \\
\hline$(1-B)^{2} \mathrm{TP}(-1)$ & -1.7618 & 0.0329 & -53.4860 & 0 \\
$(1-B)^{2} \mathrm{TP}(-2)$ & -1.3258 & 0.06256 & -21.2007 & 0 \\
$(1-B)^{2} \mathrm{TP}(-3)$ & -0.5283 & 0.0356 & -14.8013 & 0 \\
MA $(2)$ & -1.0268 & 0.0044 & -228.7775 & 0 \\
R-squared & 0.8351 & Mean dependent var & -0.0001 \\
Adjusted R-squared & 0.8341 & F-statistic & 835.6557 \\
Durbin-Watson stat & 2.0115 & Prob(F-statistic) & 0 \\
\hline
\end{tabular}

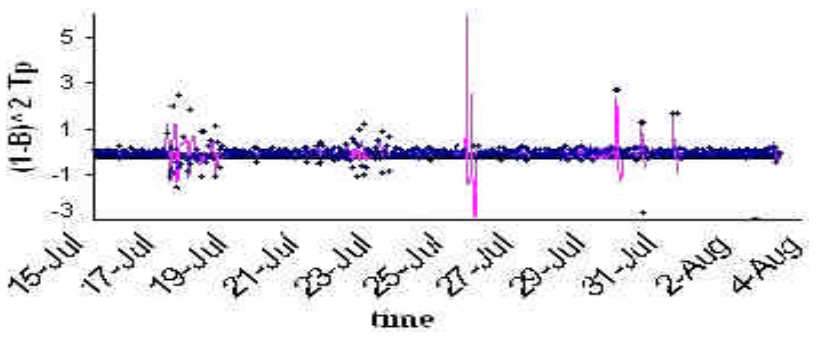

Fig. 17. Predicted (solid line) and measured (dotted line) $(1-\mathrm{B})^{2} \mathrm{Tp}$.

Acknowledgements. The authors wish to thank the office of Graduate Studies of the University of Isfahan for their support. We would like to thank the Ports and Shipping Organization of Iran for the wave data.

Topical Editor N. Pinardi thanks two referees for their help in evaluating this paper.

\section{References}

Atkinson, B. W.: Meso-scale atmospheric circulation, Academic press, London, 495, 1981.

Bendat, J. S. and Piersol, A. G.: Random Data: Analysis and Measurement Procedures, John Wiley and Sons, 566, 1986.

Box, G. E. P and Jenkins, G. M.: Time series analysis forecasting and control, San Fransisco, Holden Day, 1976.

Brockwell, P. J. and Davis, R. A.: Introduction to Time Series and Forecasting, Springer, New York, 1996.

Guedes Soares, C. and Ferreira, A. M.: Representation of nonstationary time series of significant wave height with autoregressive models, Probabilistic Engineering Mechanics, 11, 139-148, 1996.

Hidalgo, O., Nieto, J. C., Cunha, C., and Guedes Soares, C.: Filling missing observations in time series of significant wave height, in: Proceedings of the 14th International Conference on Offshore Mechanics and Arctic Engineering, edited by: Guedes Soares, C., vol. II ASME, New York, 9-17, 1995.

Hsu, S. A.: Coastal Meteorology, Academic Press, New York, 1988. Inoue, T.: On the Growth of the Spectrum of a Wind Generated Sea According to a Modified Miles-Phillips Mechanism and its Application to Wave Forecasting, Geophysical Sciences Laboratory Report No. TR-67-5, Department of Meteorology and Oceanography, New York University, 1967. 
John, V. C.: Distributions and relationships of height and period of ocean waves off Mangalore, Indian Jornal of marine Sciences, 6 , 49-50, 1985.

Longuet-Higins, M. S.: On the statistical distribution of the heights of the sea waves, Journal of Marine Research, 11, 3, 245-266, 1952.

Ramesht, M. H.: Persian Gulf geography, Isfahan University Press, 1988.
Thompson., T. S., Nelson, A. R., and Sedivy, D. G.: Wave group anatomy, Proceeding of 19th conference on Coastal engineering, American Society of Civil Engineers, 1, 661-677, 1984.

WMO: Guide to wave analysis and forecasting, No. 702, Secretariat of World Meteorological Organization, Geneva, 1988. 